\title{
Drugs Use or Abuse; Pharmacological Considerations
}

\author{
Khalid Aftab* \\ Department of Pharmacology \& Therapeutics, Sialkot Medical College, Sialkot, Pakistan \\ *Corresponding author: Khalid Aftab, Department of Pharmacology \& Therapeutics, Sialkot Medical College, Sialkot, Pakistan. \\ To Cite This Article: Khalid Aftab. Drugs Use or Abuse; Pharmacological Considerations. Am J Biomed Sci \& Res. 2019 - 5(3). AJBSR.MS.ID.000912. \\ DOI: 10.34297/AJBSR.2019.05.000912.
}

Received: 鮆September 09, 2019; Published: 眥 September 24, 2019

\section{Introduction}

The most common and essential aspects of patient care when emergencies or urgencies have arisen consist of a thorough primary assessment of the patient and airway treatment. Once this is accomplished the need for drug administration and possible EMS (emergency medical service) assistance is determined. There are no reports of toxicities from degradation products of currently available drugs. How much of potency retain varies with the drug, the lot and the storage conditions, temperature, especially humidity, but many drugs stored under reasonable conditions in their original unopened containers retain ninety percent of their potency for at least three to five years after the expiration date on the label, and sometimes much longer.(with exception of Biological Pharmaceutical Products) Drugs in solution, particularly injectable that have become clear, transparent, cloudy or discolored or show signs of precipitation, should not be used [1]. Generally drugs are an important cause of liver injury. More than nine hundred drugs, toxins, and herbs have been reported to cause liver injury, and drugs account for twenty to forty percent of all instances of fulminate hepatic failure. Approx. seventy-five percent of the idiosyncratic reactions result in liver transplantation or death.

Following are the pathological manifestations of drug-induced hepatotoxicity:

a) Acute hepatocellular injury.

b) Acute viral hepatitis-like picture - INH, Halothane, Diclofenac, Troglitazone.

c) Mononucleosis like picture - Phenytoin, Sulfonamides, Dapsone.

d) Chronic hepatocellular injury - Pemoline, Methyldopa.

Sometimes medication errors occur in the treatment of patients with renal insufficiency and can cause serious adverse effects. Although computerized systems that adjust the drug dose on the basis of a patient's glomerular filtration rate may reduce the incidence and severity of drug prescription errors, other variables may also affect the susceptibility of patients with renal dysfunction to drug toxicity. Problematic drugs whose use in patients with renal insufficiency is nephrologically contraindicated: Pethidine, Cefepime, Lithium, Gilbenclamide, Gimepiride, Metformin, Spironolactone, Eplerenone, Methotrexate, Gadolinium, Enoxaparin etc. General practitioners need the knowledge, skills, drugs and modern equipments for treating emergencies. Clinics need medical examination rooms and doctor's bags that enable emergencies to be managed onsite and offsite respectively. Rural medical generalists may provide more advanced emergency treatment in their local hospitals. In treating emergencies, General practitioners may be working with medical staff (paramedics), therefore it helps to be familiar with their skills and with the drugs they carry. This is a brief guide to some of the drugs mentioned in this article. It is by no means exhaustive and does not cover all contraindications or dosage alterations indifferent conditions. Information about these areas should be obtained elsewhere. The dosages below are guides only. Drug therapy should always be adjusted to the individual patient conditions.

\section{Allergy}

To treat allergy and hypersensitivity following drugs are commonly used in emergency

department of a hospital

a) Hydrocortisone sodium succinate injection, 100mg powder for reconstitution

b) Adrenaline 1 in $1,000(1 \mathrm{mg} / \mathrm{mL})$

c) Chlorphenamine tablets $4 \mathrm{mg}$

d) Chlorphenamine injection $10 \mathrm{mg} / \mathrm{mL}$

\section{Painkillers}

a) Paracetamol tablets $500 \mathrm{mg}$

b) Diclofenac $75 \mathrm{mg} / 3 \mathrm{~mL}$

Anti-Narcotic: Naloxone injection 400 micrograms/mL 
Antibiotics: Patients may encounter a variety of infections which may be caused by pathogenic micro

organisms.

a) Amoxicillin capsules / Co-amoxiclav tablets and dry suspension
b) Cefuroxime injection
c) Cefalexin capsules
d) Metronidazole tablets
e) Benzylpenicillin injection $600 \mathrm{mg}$ vial

\section{Cardiac Drugs}
a) Aspirin tablets $300 \mathrm{mg}$
b) Atropine injection 600 micrograms $/ \mathrm{mL}$
c) Digoxin tablets 250 micrograms
d) Furosemide injection $50 \mathrm{mg} / 5 \mathrm{~mL}$
e) Lidocaine $2 \%, 5 \mathrm{~mL}(100 \mathrm{mg}$ bolus $)$
f) Glyceryl trinitrate spray

\section{Central Nervous System}
a) Diazepam injection $10 \mathrm{mg} / 2 \mathrm{~mL}$
b) Diazepam tablets $5 \mathrm{mg}$
c) Diazepam rectal tubes $5 \mathrm{mg} / 2.5 \mathrm{~mL}$
d) Chlorpromazine injection $50 \mathrm{mg} / 2 \mathrm{~mL}$
e) Chlorpromazine tablets $25 \mathrm{mg}$
f) Haloperidol injection $5 \mathrm{mg} / \mathrm{mL}$

\section{Diabetes}
a) Glucagon injection $1 \mathrm{mg} / \mathrm{mL}$
b) Glucose solution $50 \%$

\section{Gastro-Intestinal Tract}
a) Prochlorperazine injection $12.5 \mathrm{mg} / \mathrm{mL}$
b) Loperamide capsules $2 \mathrm{mg}$
c) Gaviscon tablets

\section{Obstetrics}

Syntometrine injection (Ergometrine maleate 500 micrograms and Oxytocin 5 units $/ \mathrm{mL}$ )

\section{Ophthalmology}
a) Chloramphenicol eye ointment $1 \%$
b) Fluorescein eye drops $1 \%$

\section{Paediatric}
a) Paracetamol sachets $240 \mathrm{mg}$
b) Dioralyte sachets

\section{Respiratory System}
a) Aminophylline injection $250 \mathrm{mg} / 10 \mathrm{~mL}$
b) Hydrocortisone sodium succinate injection, $100 \mathrm{mg}$ powder for reconstitution
c) Prednisolone tablets $5 \mathrm{mg}$
d) Salbutamol or Terbutaline inhaler
e) Salbutamol for nebuliser
f) Ipratropium for nebuliser

\section{Water for Injections etc.}

Last but not the least pregnancy risk information: An update are available for consideration. In 2015 the FDA (Federal Drug Administration) replaced the former pregnancy risk letter categories on prescription and biological drug labeling with new information to make them more meaningful to both patients and healthcare professionals. The FDA received comments that the old five-letter system left patients and providers ill-informed and resulted in false assumptions about the actual meaning of the letters [2].

The new labeling system conveys better patient-specific information \& counseling decision making for pregnant lady seeking medication therapies. While the new labeling improves the old format, it still does not provide a definitive "yes" or "no" answer in most cases. Clinical interpretation is still required on a case-by-case basis. The PLLR (Pregnancy and Lactation Labeling Final Rule) is into effect on June 30, 2015; however, the timelines for implementing this new information on drug labels (also known as the packaging insert) are variable. Prescription drugs submitted for FDA approval after June 30, 2015 will use the new format, while labeling for prescription drugs approved on or after June 30, 2001 will be phased in gradual Medications approved prior to June 29, 2001 are not subject to the PLLR rule; however, the pregnancy letter category must be removed by June 29, 2018. For generic drugs, if the labeling of a reference listed drug is updated as a result of the final rule, the ANDA (abbreviated new drug application) labeling must also be revised. Labeling for OTC (over the counter) medicines will not change, as OTC drug products are not affected by the new FDA pregnancy labeling [3].

\section{Category A}

a) Adequate and well-controlled studies have failed to demonstrate a risk to the fetus in the first trimester of pregnancy (and there is no evidence of risk in later trimesters). 
b) Example drugs or substances: Levothyroxine, Folic acid, Liothyronine

\section{Category B}

a) Animal reproduction studies have failed to demonstrate a risk to the fetus and there are no adequate and well-controlled studies in pregnant women.

b) Example drugs: Metformin, Hydrochlorothiazide, Cyclobenzaprine, Amoxicillin

\section{Category C}

a) Animal reproduction studies have shown an adverse effect on the fetus and there are no adequate and well-controlled studies in humans, but potential benefits may warrant use of the drug in pregnant women despite potential risks.

b) Example drugs: Gabapentin, Amlodipine, Trazodone

\section{Category D}

a) There is positive evidence of human fetal risk based on adverse reaction data from investigation or marketing experience or studies in humans, but potential benefits may warrant use of the drug in pregnant women despite potential risks.

b) Example drugs: Losartan

\section{Category X}

a) Studies in animals or humans have demonstrated fetal abnormalities and/or there is positive evidence of human fetal risk based on adverse reaction data from investigation or marketing experience, and the risks involved in use of the drug in pregnant women clearly outweigh potential benefits.

b) Example drugs: Atorvastatin, Simvastatin, Methotrexate Finasteride

The A, B, C, D and X risk categories, in use since 1979, are now replaced with narrative sections and subsections to include:

\section{Pregnancy (includes Labor and Delivery)}

a) Pregnancy Exposure Registry

b) Risk Summary

c) Clinical Considerations

d) Data

\section{Lactation (includes Nursing Mothers)}

a) Risk Summary

b) Clinical Considerations

c) Data

\section{Female and Male of Reproductive Potential}

a) Pregnancy Testing

b) Contraception

c) Infertility

d) The former pregnancy categories, which still may be found in some package inserts, were as follows:

In view of all above Pharmacological considerations (Hepato or Nephro toxicities) physical situations \& vital conditions of patient, either regular or follow-up, emergency / casualty and urgencies and especially during pregnancy, what drugs categories \& choices are available in stable and active form for the benefit of recipients?

\section{References}

1. Abramowicz M (2009) Drugs past their expiration date. Med Lett Drugs Ther 51: 101-102.

2. Aftab, K. (2018) Medication in Pregnancy. EC Pharmacology and Toxicology, SI 1: 24-26

3. (2008) Content and Format of Labeling for Human Prescription Drug and Biological Products; Requirements for Pregnancy and Lactation Labeling 73(104). 